Article

\title{
Development of Chlorhexidine Loaded Halloysite Nanotube Based Experimental Resin Composite with Enhanced Physico-Mechanical and Biological Properties for Dental Applications
}

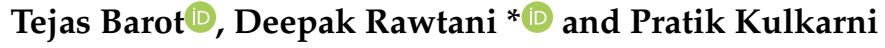 \\ Institute of Research and Development, Gujarat Forensic Sciences University, sector 9, near Police Bhawan, \\ Gandhinagar 382007, Gujarat, India; tejasbarot18@gmail.com (T.B.); pratik619prasad@gmail.com (P.K.) \\ * Correspondence: rawtanid@gmail.com; Tel.: +91-9408276489
}

Received: 25 May 2020; Accepted: 23 June 2020; Published: 25 June 2020

\begin{abstract}
Objective: The objective of this study was to explore the effect of Chlorhexidine-loaded Halloysite nanotubes (HNT/CHX) fillers (diverse mass fractions from 1 to $10 \mathrm{wt} . \%$ ) on physicochemical, morphological and biological properties of newly developed experimental dental resin composite, in order to compare with the properties of composites composed of conventional glass fillers. Methods: The dental resin composites were prepared by incorporating various proportions of HNT/CHX. Six different groups of specimens: control group and five groups composed of varied mass fractions of HNT/CHX (e.g., 1.0, 2.5, 5.0, 7.5 and $10 \mathrm{wt} . \%$ ) as fillers in each group were fabricated. Mechanical properties of the composites were monitored, using UTM. The degree of conversion of dental resin composites and their depth of cure were also evaluated. Antimicrobial properties of dental composites were studied in vitro by applying agar diffusion test on strain Streptococcus mutans and cytotoxicity were studied using NIH-3T3 cell line. Results: The incorporation of varied mass fractions (1.0 to $5.0 \mathrm{wt} . \%$ ) of $\mathrm{HNT} / \mathrm{CHX}$ in dental resins composites enhanced mechanical properties considerably with significant antibacterial activity. The slight decrease in curing depth and degree of conversion values of composites indicates its durability. No cytotoxicity was noticed on NIH-3T3 cell lines. Significance: Consistent distribution of HNT/CHX as a filler into dental composites could substantially improve not only mechanical properties but also biological properties of dental composites.
\end{abstract}

Keywords: dental composites; Halloysite nanotubes; mechanical properties; antimicrobial activity; cytotoxicity

\section{Introduction}

Oral diseases are highly prevalent and can significantly affect human health, especially untreated carious teeth. Resin-based composites have been used as dental restorative materials for a long time [1]. Compared to dental amalgam, dental composites are more preferred by dental practitioners due to dental composites having low toxicity, high biocompatibility and strong bonding properties to teeth $[2,3]$. Extensive efforts have been made to enhance mechanical and biological properties for dental composites for different applications $[4,5]$. The major limitations associated with dental resin composites are their lack of adequate physico-mechanical properties and antibacterial properties, which leads to fracture or secondary dental carries and eventually failure of composite restoration $[6,7]$. The microscopic marginal gaps between the teeth and filling material may harbor bacteria and encourage bacterial proliferation, which in-turn leads to secondary carries [8]. Therefore, developing novel dental composites with superior mechanical properties, along with antibacterial properties, 
would be advantageous to patients. An antibacterial dental composite may prevent secondary caries by preventing oral biofilm formation on tooth surfaces [8,9].

Halloysite nanotubes (HNTs) $\left(\mathrm{Al}_{2} \mathrm{Si}_{2} \mathrm{O}_{5}(\mathrm{OH})_{4} \cdot 2 \mathrm{H}_{2} \mathrm{O}\right)$ are a two-layered alumino-silicate with tubular structure. Halloysite is mineral which is available abundantly in nature and inexpensive compared to carbon nanotubes (CNT) [10]. As per the earlier report, CNTs were found to be toxic to cells, and their cytotoxicity increases with surface functionalization with acid treatment [11]. In addition, Halloysite is biocompatible in nature and easy to purify. It has diameters in tens of nanometers, and the lengths range from $\sim 200 \mathrm{~nm}$ to $1-2 \mu \mathrm{m}$ [12]. In recent years, HNTs have been seen as potential nanocarrier agents for the delivery of drugs $[4,10]$.

Chlorhexidine ( $\mathrm{CHX})$ has a broad spectrum of antimicrobial activity against various organisms, such as bacteria, fungi and viruses. It used widely in denture-wash liquid, oral mouth rinse and hand sanitizer [13]. Chlorhexidine acts by disrupting cell membranes of micro-organisms and has low cytotoxicity [14].

This study focused on the investigation of experimental dental resin composites made from HNT nanocarrier loaded with Chlorhexidine. The constant distribution of well-separated HNT/CHX into dental composites would result in the enhancement of mechanical and antibacterial properties. The structure of HNT/CHX was examined by Fourier-transform infrared spectroscopy (FTIR) and X-ray diffractometer (XRD). The experimental dental composites were tested for their Compressive Strength, Flexural Strength, Flexural Modulus, depth of cure and degree of conversion. Streptococcus mutans (S. mutans) was used as an in-vitro surrogate model for testing antibacterial efficiency of the dental resin composite. MTT assay was performed on NIH 3T3 cell lines, to assess the cytotoxicity of the dental resin composite. The morphology of a fractured dental composite was observed under scanning electron microscopy (SEM) and transmission electron microscope (TEM).

\section{Materials and Methods}

\subsection{Materials}

Bis-GMA and TEGDMA (Bisphenol A glycerolate dimethacrylate and tri (ethyleneglycol) dimethacrylate, 95\%) were provided by the Esstech Co. (Essington, PA, USA). Chlorhexidine digluconate was procured from Macleod's pharma (Mumbai, India). Camphorquinone (CQ, 97\%) and Ethyl-4-dimethylaminobenzoate (4-EDMAB, 99\%) were procured from TCI Chemicals Pvt. Ltd. (Chennai, India) Pvt Ltd. Purified Halloysite nanotubes was acquired from Sigma-Aldrich Co. (Bengaluru, India). The dental glass filler (V-117-1190) was provided by the Esstech Co. (Essington, PA, USA) for this study.

\subsection{Methods}

\subsubsection{Drug Loading into HNTs}

Chlorhexidine digluconate $\left(20 \mathrm{mg} \mathrm{mL}^{-1}\right)$ was first dissolved in double-distilled water at $80^{\circ} \mathrm{C}$ for $45 \mathrm{~min}$. The mixture was then sonicated until the drug dissolved entirely. Then, the sieved HNTs (via a $45 \mu \mathrm{m}$ sieve) $\left(1 \mathrm{mg} \mathrm{mL}^{-1}\right)$ were added to the drug solution. Then, ultra-sonication was done for $1 \mathrm{~h}$, to disperse HNTs in the drug solution. Afterward, the solution was subjected to vacuum at $0.085 \mathrm{Mpa}$, letting the drug solution enter within the hollow lumens of HNTs. The resultant solution was taken out and kept at atmospheric pressure for $15 \mathrm{~min}$; after some time, vacuum was applied again, to remove any remnant air in the hollow tubules. Any fizzing indicated the presence and removal of air in the course of the vacuuming procedure. This cycle was repeated 5 times [15]. The resultant mixture was washed with double-distilled water to eliminate any free-floating drug. These drug-loaded HNT samples were dried in the air and preserved for future evaluations. 


\subsubsection{Preparation of Dental Resin Composites}

A formulation with Bis-GMA/TEGDMA in the ratio of 69.5/29.5 wt./wt., with CQ/4-EDMAB as a photo-initiators in ratio of 0.5/0.5 wt./wt., was used as the resin matrix [16]. For the fabrication of resin-composite samples without dental glass fillers, six different groups of resin-composite specimens were prepared: the control group, $\mathrm{H} 1(0 \%)$, and five groups containing varied mass fractions with HNT/CHX in each group, namely H2 (1\%), H3 (2.5\%), H4 (5\%), H5 (7.5\%) and H6 (10\%). The details of varied mass fractions of HNT/CHX without glass fillers in dental composites are shown in Table 1.

Table 1. The composition of dental resin composite containing HNT/CHX in the resin matrix without glass fillers and the light-curing time.

\begin{tabular}{|c|c|c|c|c|c|}
\hline Groups & $\%$ wt. of HNT/CHX & Resin (Matrix) & Other Component & Light-Curing Time (s) & No. of Samples \\
\hline H1 (Control) & 0 & $\begin{array}{c}\text { Bis-GMA/TEGDMA } \\
69.5 / 29.5 \text { wt. } \%\end{array}$ & $\begin{array}{c}\mathrm{CQ}^{\mathrm{a}} / 4-\mathrm{EDMAB}^{\mathrm{b}} \\
0.5 / 0.5 \text { wt. } \%\end{array}$ & 40 & 6 \\
\hline H2 & 1 & $\begin{array}{c}\text { Bis-GMA/TEGDMA } \\
69.5 / 29.5 \text { wt. } \%\end{array}$ & $\begin{array}{c}\mathrm{CQ}^{\mathrm{a}} / 4-\mathrm{EDMAB}^{\mathrm{b}} \\
0.5 / 0.5 \text { wt. } \%\end{array}$ & 40 & 6 \\
\hline H3 & 2.5 & $\begin{array}{c}\text { Bis-GMA/TEGDMA } \\
69.5 / 29.5 \text { wt. } \%\end{array}$ & $\begin{array}{c}\mathrm{CQ}^{\mathrm{a}} / 4-\mathrm{EDMAB}^{\mathrm{b}} \\
0.5 / 0.5 \mathrm{wt} . \%\end{array}$ & 40 & 6 \\
\hline $\mathrm{H} 4$ & 5 & $\begin{array}{c}\text { Bis-GMA/TEGDMA } \\
69.5 / 29.5 \text { wt. } \%\end{array}$ & $\begin{array}{c}\mathrm{CQ}^{\mathrm{a}} / 4-\mathrm{EDMAB}^{\mathrm{b}} \\
0.5 / 0.5 \mathrm{wt} . \%\end{array}$ & 40 & 6 \\
\hline H5 & 7.5 & $\begin{array}{c}\text { Bis-GMA/TEGDMA } \\
69.5 / 29.5 \text { wt. } \%\end{array}$ & $\begin{array}{c}\mathrm{CQ}^{\mathrm{a}} / 4-\mathrm{EDMAB}^{\mathrm{b}} \\
0.5 / 0.5 \mathrm{wt} . \%\end{array}$ & 40 & 6 \\
\hline H6 & 10 & $\begin{array}{c}\text { Bis-GMA/TEGDMA } \\
69.5 / 29.5 \text { wt. } \%\end{array}$ & $\begin{array}{c}\text { CQ }^{\mathrm{a}} / 4-\mathrm{EDMAB}^{\mathrm{b}} \\
0.5 / 0.5 \mathrm{wt} . \%\end{array}$ & 40 & 6 \\
\hline
\end{tabular}

${ }^{\mathrm{a}}$ Camphorquinone, ${ }^{\mathrm{b}}$ Ethyl-4-dimethylaminobenzoate. HNT/CHX-Chlorhexidine-loaded Halloysite nanotubes.

Furthermore, HNT/CHX resin was mixed with dental glass fillers, and six different groups of resin composite specimens were prepared: control group, G1 (0\%), and five groups containing varied mass fractions, namely G2 (1\%), G3 (2.5\%), G4 (5\%), G5 (7.5\%) and G6 (10\%) (The combined ratio of glass fillers and $\mathrm{HNT} / \mathrm{CHX}$ being limited to $70 \%$ ). The data pertaining to different mass fractions of HNT/CHX with glass fillers in dental resin composites are given in Table 2.

Table 2. The Composition of dental resin composite containing HNT/CHX in the resin matrix with glass fillers and the light-curing.

\begin{tabular}{|c|c|c|c|c|c|c|}
\hline Groups & $\begin{array}{l}\text { \% wt. of } \\
\text { HNT/CHX }\end{array}$ & $\begin{array}{c}\% \text { wt. of } \\
\text { Glass Fillers }\end{array}$ & Resin (Matrix) & Other Component & Light-Curing Time (s) & No. of Samples \\
\hline G1 (Control) & 0 & 70 & $\begin{array}{c}\text { Bis-GMA/TEGDMA } \\
69.5 / 29.5 \mathrm{wt} . \%\end{array}$ & $\begin{array}{c}\text { CQ }^{\mathrm{a}} / 4-\mathrm{EDMAB}^{\mathrm{b}} \\
0.5 / 0.5 \text { wt. } \%\end{array}$ & 40 & 6 \\
\hline G2 & 1 & 69 & $\begin{array}{c}\text { Bis-GMA/TEGDMA } \\
69.5 / 29.5 \text { wt. } \%\end{array}$ & $\begin{array}{c}\text { CQ }^{\mathrm{a}} / 4-\mathrm{EDMAB}^{\mathrm{b}} \\
0.5 / 0.5 \text { wt. } \%\end{array}$ & 40 & 6 \\
\hline G3 & 2.5 & 67.5 & $\begin{array}{c}\text { Bis-GMA/TEGDMA } \\
69.5 / 29.5 \text { wt. } \%\end{array}$ & $\begin{array}{c}\mathrm{CQ}^{\mathrm{a}} / 4-\mathrm{EDMAB}^{\mathrm{b}} \\
0.5 / 0.5 \mathrm{wt} . \%\end{array}$ & 40 & 6 \\
\hline G4 & 5 & 65 & $\begin{array}{c}\text { Bis-GMA/TEGDMA } \\
69.5 / 29.5 \text { wt. } \%\end{array}$ & $\begin{array}{c}\mathrm{CQ}^{\mathrm{a}} / 4-\mathrm{EDMAB}^{\mathrm{b}} \\
0.5 / 0.5 \mathrm{wt} . \%\end{array}$ & 40 & 6 \\
\hline G5 & 7.5 & 62.5 & $\begin{array}{c}\text { Bis-GMA/TEGDMA } \\
69.5 / 29.5 \text { wt. } \%\end{array}$ & $\begin{array}{c}\mathrm{CQ}^{\mathrm{a}} / 4-\mathrm{EDMAB}^{\mathrm{b}} \\
0.5 / 0.5 \mathrm{wt.} \%\end{array}$ & 40 & 6 \\
\hline G6 & 10 & 60 & $\begin{array}{c}\text { Bis-GMA/TEGDMA } \\
69.5 / 29.5 \text { wt. } \%\end{array}$ & $\begin{array}{c}\mathrm{CQ}^{\mathrm{a}} / 4-\mathrm{EDMAB}^{\mathrm{b}} \\
0.5 / 0.5 \mathrm{wt} . \%\end{array}$ & 40 & 6 \\
\hline
\end{tabular}

${ }^{a}$ Camphorquinone, ${ }^{b}$ Ethyl-4-dimethylaminobenzoate. HNT/CHX-Chlorhexidine-loaded Halloysite nanotubes.

The HNT/CHX was added in the TEGDMA-containing beaker, under mechanical stirring at $500 \mathrm{rpm}$ for $1 \mathrm{~h}$. Then, Bis-GMA, 4EDMAB and CQ were added under continuous stirring at $500 \mathrm{rpm}$ for another $1 \mathrm{~h}$. Afterward, the prepared system was kept under vacuum for $24 \mathrm{~h}$ at $25^{\circ} \mathrm{C}$, to remove air bubbles. Afterward, the resultant composite paste was placed in molds of silicon rubber, and the glass slide was used on both sides, to cover mold the surface [17]. Afterward, the molds were photo-polymerized with an LED curing unit (Woodpecker i-LED, China), for $40 \mathrm{~s}$ on each side [17-19]. The prepared composite specimen was then kept in dark airtight containers for 3 days, at room temperature, and polished progressively with silicon carbide abrasive papers (P1500 grit) prior to evaluation. 


\subsection{Characterization}

\subsubsection{Characterization of Inorganic Fillers}

(1) Morphology of HNT/CHX and HNTs

Ultrastructural analyses of HNTs and HNT/CHX were conducted by Transmission Electron Microscope (Model G2 F30, FEI Technai, Eindhoven, Netherlands), with the intention of confirming the CHX loading with HNT at voltage around $300 \mathrm{kV}$. The samples were fabricated by dispersing the drug-loaded HNTs in n-propanol for 5-10 min, under ultra-sonication. During this procedure, micro-pipettes were used to collect a minute quantity of the solution, which was then placed over a copper grid (carbon-coated) [18]. The grid was settled for $10 \mathrm{~min}$, and then it was used for TEM analysis.

The morphology of fracture surfaces of dental composites containing HNT/CHX were also examined by Scanning Electron Microscope (SEM, Zeiss EVO 18, Jena, Germany). Ahead of SEM examination, all sample specimens were mounted on stubs and vacuum-coated with Palladium-Gold film, to avoid charge accumulation [19].

(2) Diffraction studies of HNT, CHX and HNT/CHX

X-ray diffraction (XRD) spectra of HNT, CHX and HNT/CHX were recorded on an X-ray GNR APD $2000 \mathrm{PRO}$, using Ni-filtered $\mathrm{CuK} \alpha$ as radiation source with wavelength of $1.54 \AA$ in the configuration of Bragg-Brentano. The instrument was run at $40 \mathrm{kV}$ and $30 \mathrm{~mA}$. Around $600 \mathrm{mg}$ of the powered sample was taken in the sample holder, and then the sample holder was placed on the instrument for analysis. XRD data were recorded at a scanning speed of around $1 \mathrm{~min}^{-1}$, from $10^{\circ}$ to $80^{\circ}(2 \theta)[18,19]$.

(3) Fourier-transform-infrared spectroscopy (FTIR) analysis

The infrared vibration spectrum of HNT, CHX and HNT/CHX was obtained by using FTIR-JASCO 4100. To carry out the analysis, the sample was mixed in 1:100 ratios with potassium bromide (KBr). A pellet press was used to create pellet from the mixture. The background spectrum was recorded by blank KBr pellet, and then pellet with samples were recorded. The spectral range for analysis was kept at $4000-400 \mathrm{~cm}^{-1}$ wave range, at $4 \mathrm{~cm}^{-1}$ resolutions and 32 scans.

\subsubsection{Characterization of Dental Resin Composites}

(1) Mechanical properties

Flexural Strength (FS), Compressive Strength (CS), and Flexural Modulus (FM) of dental resin composite were recorded, using a Universal Testing Machine (UTM, Lloyd LRX, West Sussex, UK). As per ANSI/ADA specification no. 27/2009 (ISO-4049), six specimens with rectangular dimension $(25 \mathrm{~mm} \times 2 \mathrm{~mm} \times 2 \mathrm{~mm})$ were made from composite paste and irradiated for $40 \mathrm{~s}$ on each side.

A 3-point bending test (with $20 \mathrm{~mm}$ stretch) and cross-head speed $(1 \mathrm{~mm} / \mathrm{min})$ were used to measure Flexural Strength and Flexural Modulus of the cured dental composite specimens. The Flexural Strength was computed with $3 \mathrm{PL} / 2 \mathrm{bd} 2$ formula, where $\mathrm{P}=$ load at fracture; $\mathrm{L}=$ span length; $\mathrm{b}=$ width; and $\mathrm{d}=$ thickness [19]. Additionally, to measure CS of cured composite samples, cylindrical type specimens $(\phi 4 \mathrm{~mm} \times 6 \mathrm{~mm}, \mathrm{n}=6)$ were also crafted and evaluated, using universal testing with cross-head speed of $1 \mathrm{~mm} / \mathrm{min}$.

(2) Degree of conversion

The degree of conversion (DC) of cured dental composite specimen was analyzed, using FTIR spectrometer (JASCO 4700), equipped with ATR (attenuated total reflectance crystal). The spectral range for FTIR analysis was maintained at $4000-400 \mathrm{~cm}^{-1}$ wave range, at $4 \mathrm{~cm}^{-1}$ resolutions and 32 scans [20]. Vibrational spectra were recorded for each specimen before and after curing. The DC of each specimen was calculated by the ratio of absorbance intensities of aliphatic C-C bond $\left(1638 \mathrm{~cm}^{-1}\right)$, with reference to internal standard of aromatic C-C bond $\left(1608 \mathrm{~cm}^{-1}\right)$. The trials were repeated three times for every specimen. The DC (\%) of the specimen calculated from Formula (1) is as follows:

$$
\mathrm{DC}(\%)=(1-\mathrm{R} \text { cured } / \mathrm{R} \text { uncured }) \times 100
$$


where $\mathrm{R}=$ band height at $1638 \mathrm{~cm}^{-1} /$ band height at $1608 \mathrm{~cm}^{-1}$.

(3) Curing depth

The silicon mold $(\phi 4 \mathrm{~mm} \times 6 \mathrm{~mm})$ was filled with composite paste, uniformly, and irradiated vertically for $20 \mathrm{~s}$, with the curing module, according to ISO 4049 [20]. The cured sample was taken away from the silicon mold, and uncured paste was removed with the help of spatula. The curing depth of the specimen at different orientations was measured by using a digital caliper, 5 times $(n=3$, accurate to $0.01 \mathrm{~mm}$ ).

(4) Antimicrobial assessments

A Gram-positive strain of Staphylococcus mutans (MTCC 890) was used to assess the antibacterial activity of HNT/CHX dental resin composites [21]. The sensitivity of $S$. mutans toward resin composites was studied by using Disk diffusion assay, under aseptic conditions, in a laminar airflow chamber. The specimens were formed with resin composite paste, using silicon rubber molds with a diameter of $6 \mathrm{~mm}$ and thickness of $2 \mathrm{~mm}$. The specimens were made by placing the respective materials into the mold over a glass slab sandwiched between two Mylar strips. The material was light-cured for $40 \mathrm{~s}$ on each side [19].

Lyophilized S. mutans strains (MTCC 890) were procured from IMTECH (Institute of Microbial Technology, Chandigarh, India). They were grown in $25 \mathrm{~mL}$ of Luria Bertani (LB) Broth, (HiMedia Laboratory Pvt. Ltd., Mumbai, India), separately, at $37^{\circ} \mathrm{C}$ for $48 \mathrm{~h}$. The resultant bacteria were again kept in $25 \mathrm{~mL}$ of BHI broth (Brain Heart Infusion broth, HiMedia Laboratory Pvt. Ltd., Mumbai, India) at $37^{\circ} \mathrm{C}$ for $24 \mathrm{~h}$, to grow a suspension culture (inoculum), corresponding to $106 \mathrm{CFU} / \mathrm{mL}$, as per the McFarland scale. All polymerized specimens were immersed in $10 \mathrm{~mL}$ of $100 \%$ methanol and washed with continuous agitation, to remove any non-polymerized components, and then they were sterilized by ethylene oxide gas [22].

For the agar diffusion test, a $5 \mathrm{~mm}$ base layer containing $25 \mathrm{~mL}$ BHI agar (Brain Heart Infusion agar, HiMedia Laboratory Pvt. Ltd., Mumbai, India) was uniformly spread in disposable sterile Petri plate. After solidification of agar, sterile borers were used to form wells around $6 \mathrm{~mm}$ in diameter in each Petri plate [22].

Each Petri plate contained a maximum of 4 specimens for the test. Sterile water was used as negative and $0.12 \%$ Chlorhexidine digluconate solution as a positive control. The culture plates were kept at $37^{\circ} \mathrm{C}$ for $24 \mathrm{~h}$, in the incubator. After $24 \mathrm{~h}$ of incubation, the formed inhibition zones around the discs were observed and measured in millimeters. The diameter of each inhibition zone for each disk was measured three times, and the resultant mean was calculated $[19,23]$.

(5) In vitro cytotoxicity test

NIH-3T3 cell lines were used to examine the cytotoxicity of HNT/CHX resin composites. Optimal cell counts (5000 cells in each well) were determined for seeding in a 96-well plate of NIH-3T3 cells in $100 \mu \mathrm{L}$ media. Cells were cultured in MEM (Minimal Essential Medium), accompanied with streptomycin $(100 \mu \mathrm{g} / \mathrm{mL})$, penicillin $(100 \mathrm{U} / \mathrm{mL})$ and $10 \%$ fetal bovine serum (FBS). Plates were incubated at $37^{\circ} \mathrm{C}$ in a $5 \% \mathrm{CO}_{2}$ incubator set for $24 \mathrm{~h}$. After $24 \mathrm{~h}$, cells were treated with the samples (Positive and Negative controls, 5\% HNT/CHX) protocol in triplicate when they reached at about $40-50 \%$ confluence. Plates were incubated in $5 \% \mathrm{CO}_{2}$ incubator set at $37^{\circ} \mathrm{C}$ for 24,48 and $72 \mathrm{~h}$. After $24 \mathrm{~h}$, photographs were taken of each treatment group. Thereafter, $10 \mu \mathrm{L}$ of MTT solution (stock of $5 \mathrm{mg} / \mathrm{mL}$ ) was added to every well. The plate was incubated in $5 \% \mathrm{CO}_{2}$ incubator for $3 \mathrm{~h}$ at $37^{\circ} \mathrm{C}$, allowing the formazan crystals to form that can be observed by using the microscope. Media was pipette out gently, without disrupting the formazan crystals and discarded. Thereafter, $200 \mu \mathrm{L}$ of DMSO solution (as solubilizing buffer) was added in each well, to solubilize the formazan crystals. The plate was kept on a shaker and incubated for $15 \mathrm{~min}$. Absorbance was taken at $570 \mathrm{~nm}$. After that, IC50 values for each sample were calculated [24,25]. 


\subsubsection{Statistical Analysis}

The recorded data of FS, FM and CS were analyzed, using one-way analysis of variance (ANOVA), using SPSS software, version 20 (SPSS, Chicago, IL, USA). Significant differences were observed by using Tukey's HSD (honestly significant difference) test. References to significant differences were established on a probability of $p<0.05$, unless otherwise stated.

\section{Results}

\subsection{Morphological Evaluation}

The tubular shape and nano diameter of the Halloysite nanotubes have significant effect on the loading efficiency and sustained release profile of the drug. The ultra-structural morphology of HNTs was observed by using TEM. The nano size of the nanotube varied by approximately $1.5-2.0 \mu \mathrm{m}$ in length, $10-40 \mathrm{~nm}$ inner diameter and $30-80 \mathrm{~nm}$ in external diameter. The TEM results showed an open-ended lumen with cylindrical tubular structure of HNTs and transparent central area. After the drug loading of HNTs, the inner diameter of HNT/CHX expanded twice in size and showed the presence of the drug, indicated by dark spots in the internal lumen, thus confirming the presence of CHX [19,26-28] (Figure 1).

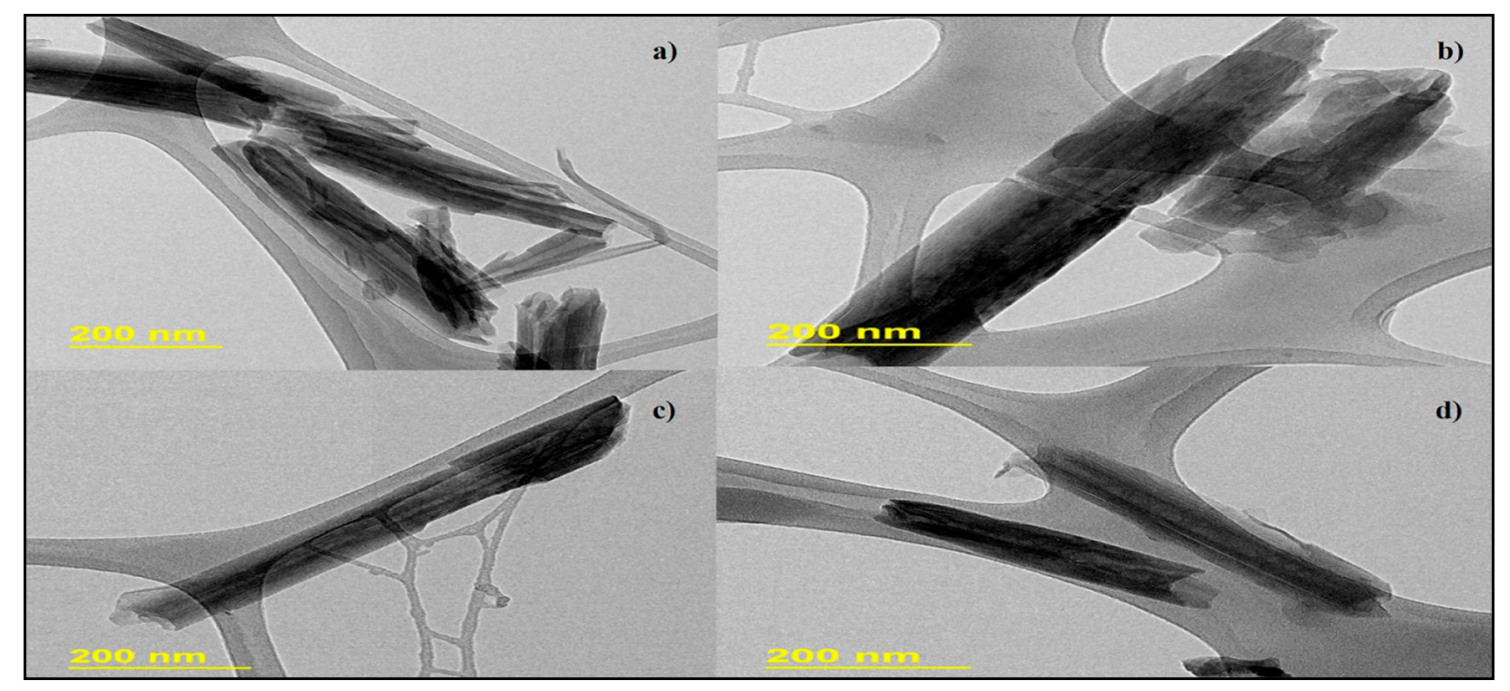

Figure 1. TEM images (a,b) of pristine Halloysite nanotubes (HNTs); (c,d) of Chlorhexidine-loaded Halloysite nanotubes (HNT/CHX).

\subsection{Diffraction Studies of HNT, CHX and HNT/CHX}

The XRD analysis of HNT, CHX and HNT/CHX was performed for the evaluation of drug loading on the crystalline structure of HNTs. The results showed characteristic diffraction peaks of pristine HNTs (ICDD \#00-060-1517) at $11.9^{\circ}, 19.9^{\circ}$ and $24.9^{\circ}$ associated with the $001,020 / 110$ and 002 basal plane which confirmed the absence of any water molecules inside the lumen $[18,29]$. CHX demonstrated characteristic peaks at $19.8^{\circ}, 20.3^{\circ}$ and $24.5^{\circ}$ in $2 \theta$. The observed HNT/CHX diffraction peaks were constant with pristine HNTs, and the interlayer distance of the HNT/CHX composite stayed unaffected. Furthermore, the diffraction peaks of both HNTs and HNT/CHX were sharp and narrow, implying that these two have highly crystalline structures. The characteristic peaks of $\mathrm{CHX}$ were absent in the CHX-loaded HNT that confirmed uniform CHX loading in the structure of the HNT/CHX, demonstrating successful loading of CHX [30] (Figure 2). 


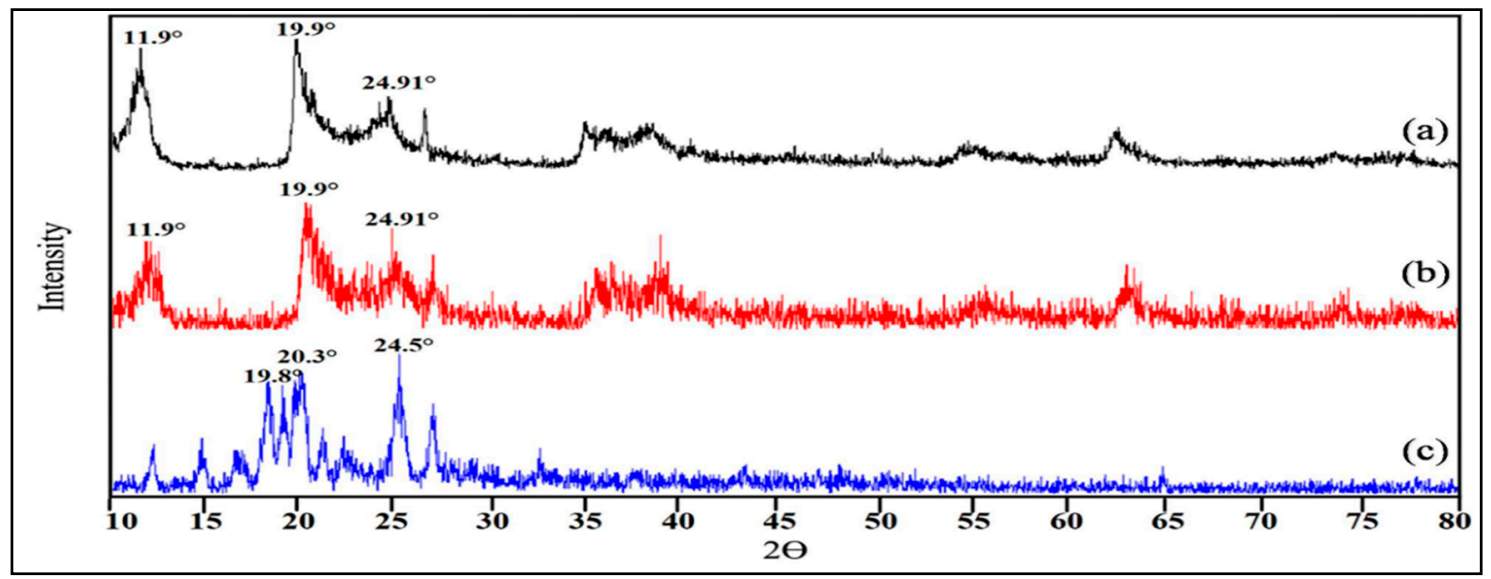

Figure 2. X-ray diffraction patterns of (a) Halloysite nanotubes (HNTs); (b) Chlorhexidine-loaded Halloysite nanotubes (HNT/CHX); (c) Chlorhexidine (CHX).

\subsection{FTIR Analysis of HNT, CHX and HNT/CHX}

Representative FTIR shows the vibrational bands obtained for the pure CHX, HNTs and the HNT/CHX (Figure 3). The spectrum for HNT showed absorption peaks at 911 and $3695 \mathrm{~cm}^{-1}$. These peaks corresponded to Al-O-OH bending and $\mathrm{O}-\mathrm{H}$ stretching, respectively [18]. A precise Si-O-Si in-plane stretching vibration of was recorded at 1091 and $1032 \mathrm{~cm}^{-1}$ [31,32]. In the CHX spectra, the vibrational peaks at 1576, 3378 and $3478 \mathrm{~cm}^{-1}$ represent NH- bending in CHX. Meanwhile, the HNT/CHX (post encapsulation of CHX in HNT) showed vibrational peaks at $1091 \mathrm{~cm}^{-1}$, and $1032 \mathrm{~cm}^{-1}$ in-plane stretching vibrations of Si-O-Si, which shifted to 1122 and $1019 \mathrm{~cm}^{-1}$; this showed a clear interaction between inner lumen Si-O-Si groups of HNT with NH- groups of CHX. The result indicates no interference with the intrinsic HNT morphology due to CHX loading [32]. Loss of major CHX peaks at 3378 and $3478 \mathrm{~cm}^{-1}$ in the HNT/CHX spectra shows the successful loading of CHX into the lumen of HNTs. However, a short peak that merged at 1634 and $1685 \mathrm{~cm}^{-1}$ may reveal that a negligible amount of drug has been adsorbed at outer surface of the HNTs as a residual drug due to electrostatic interaction [28] (Figure 3).

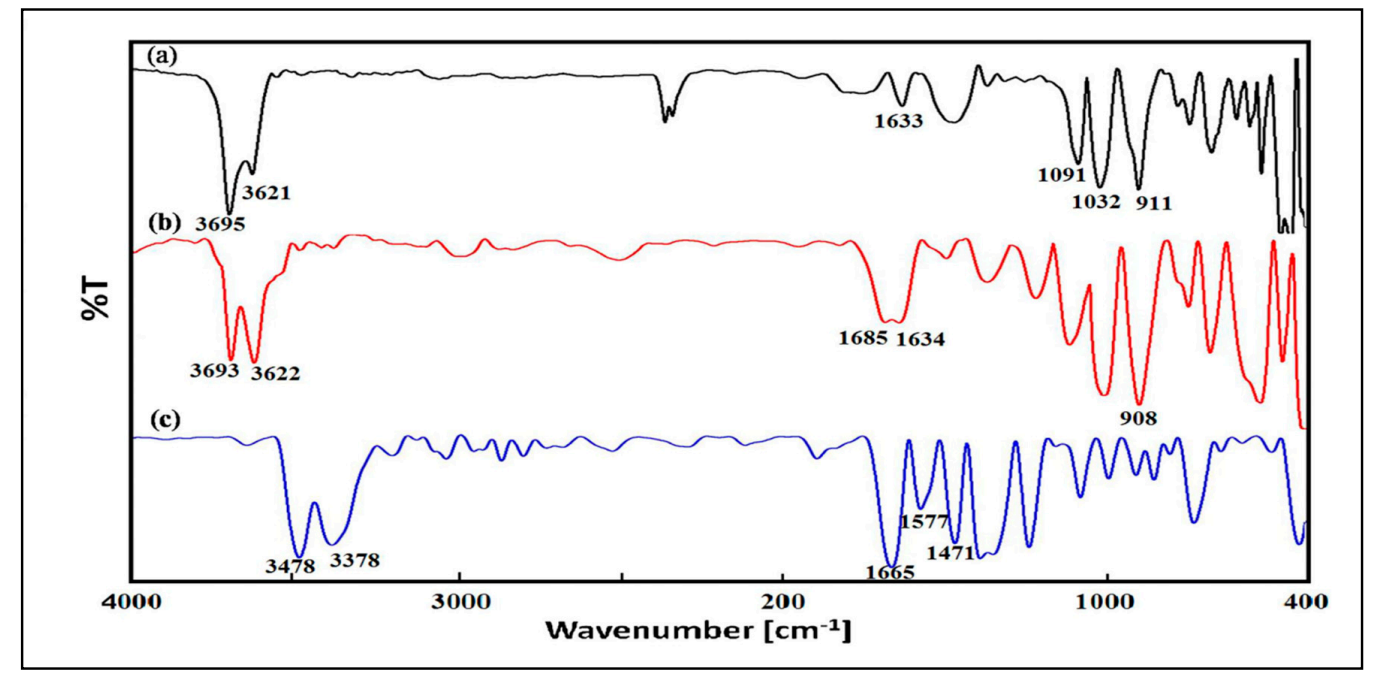

Figure 3. FTIR spectrum of (a) Halloysite nanotubes (HNTs); (b) Chlorhexidine loaded Halloysite nanotubes (HNT/CHX); (c) Chlorhexidine (CHX). 


\subsection{Properties of Dental Resin Composites}

\subsubsection{Mechanical Characterization}

The mechanical properties of dental resin composites significantly influenced by the amount of incorporated fillers. The addition of diverse mass fraction of Halloysite-nanotube-based fillers (HNT/CHX) substantially enhanced the values of FM, FS and CS of resin composites in comparison with the control group $(p<0.05)$ (Figure 4$)$.

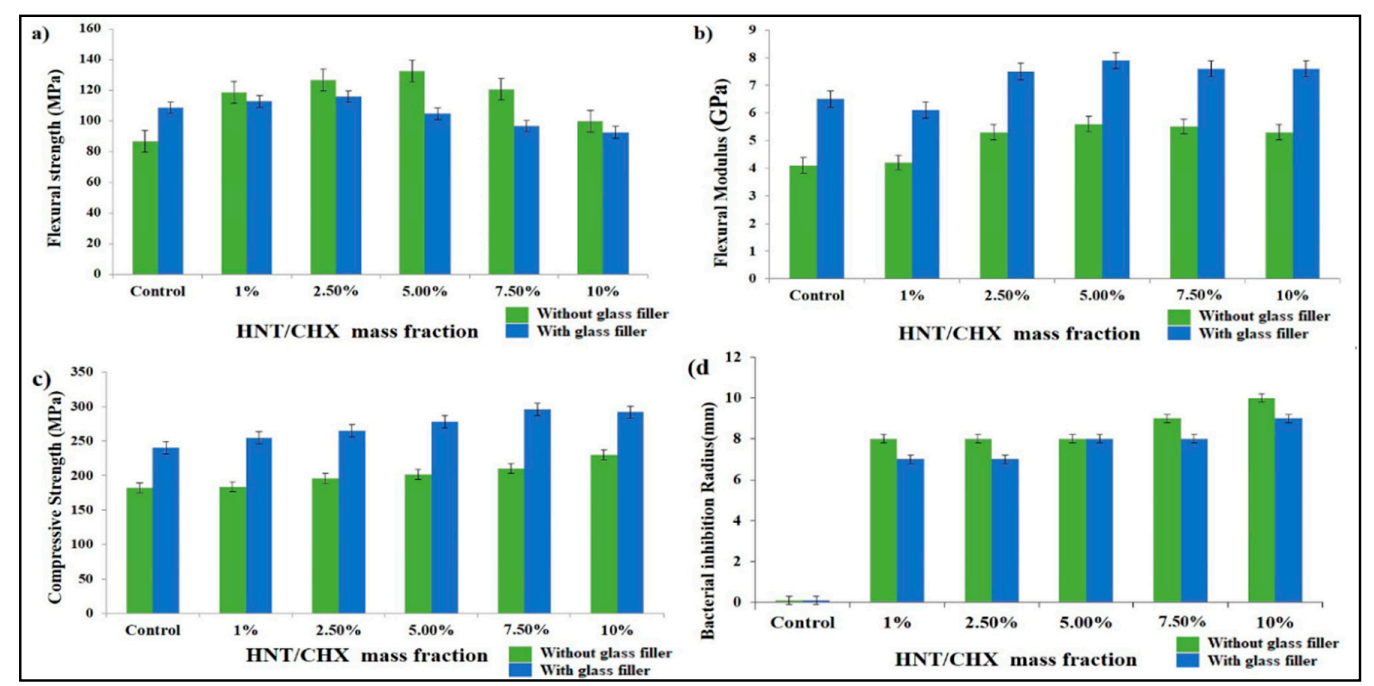

Figure 4. Mechanical properties of dental resin composites with varied amounts of HNT/CHX (1\%, 2.5\%, 5\%, 7.5\% and 10 wt.\%). (a) Flexural Strength; (b) Flexural Modulus; (c) Compressive Strength; each bar is the mean value of six samples, while the error bar represents one standard deviation ( $p$ value $<0.05)$. (d) Bacterial inhibition radius $(\mathrm{n}=3, p$ value $<0.05)$.

The mechanical properties of composite groups without glass fillers were enhanced significantly after the incorporation of HNT/CHX into the resin matrix, as compared to the control samples. The values of FS, FM and CS for the control group (H1) resin were FS-86.5 MPa, FM-4.1 GPa and CS-182 Mpa, respectively. Moreover, as the filler fraction increased from 1 to $5 \mathrm{wt} . \%(\mathrm{H} 2-\mathrm{H} 4)$, the mechanical properties also increased. However, higher loading at $7.5 \mathrm{wt.} \% \mathrm{HNT} / \mathrm{CHX}$ (H5) and 10 wt.\% HNT/CHX (H6) shows no increase in the FM, FS and CS values of the final resin composite, which may be owing to agglomeration formed by HNT/CHX [33]. The $5 \mathrm{wt} . \% \mathrm{HNT} / \mathrm{CHX}$ (H4) sample exhibited the best Flexural Strength $(132.40 \pm 2.46 \mathrm{MPa})$, Compressive Strength $(202 \pm 12.40 \mathrm{MPa})$ and Flexural Modulus (5.6 $\pm 0.44 \mathrm{GPa})$. These results displayed that HNT/CHX can be used as a reinforcement at lower loadings (Figure 4) [34].

The resin composite groups with both conventional glass filler and mass fractions of HNT/CHX displayed enhanced mechanical properties, compared to the control group. The values of FS, FM and CS for the control group (G1) resin were FS-108.5 MPa, FM-6.5 GPa and CS-240 Mpa, respectively. Similar to the previous groups of composites, the resin composite groups with both conventional glass filler and HNT/CHX showed an increase in the mechanical strength from 1 to $5 \mathrm{wt} . \%$ (G2-G4) and moderate decrease at $7.5 \mathrm{wt} . \% \mathrm{HNT} / \mathrm{CHX}$ (G5) and $10 \mathrm{wt} . \% \mathrm{HNT} / \mathrm{CHX}$ (G6). The maximum values of FS, FM and CS in these resin composite groups found at $5 \mathrm{wt} . \%$ of HNT/CHX (G4) were FS-104.5 MPa, FM-7.9 GPa and CS-278.5 MPa, which is significantly higher among all specimen groups (Figure 4).

\subsubsection{Degree of Conversion}

The degree of conversion of the dental composite was monitored by FTIR-ATR. It was observed that integration of $\mathrm{HNT} / \mathrm{CHX}$ in a 1 to $10 \mathrm{wt} . \%$ proportion presented a moderate decrease in the DC, 
as compared to the control group. The DC values of all HNT/CHX dental composite specimens varied from $72 \%$ to $65 \%$. The degree of conversion of all light-cured composite specimens (without glass filler and with glass filler) remains high. The results indicate that the DC values of the HNT/CHX composite without glass fillers is slightly higher than that of the composite consisting of HNT/CHX with glass filler. These results were in accordance with some previous reports, whereby similar results were obtained [35,36] (Figure 5).

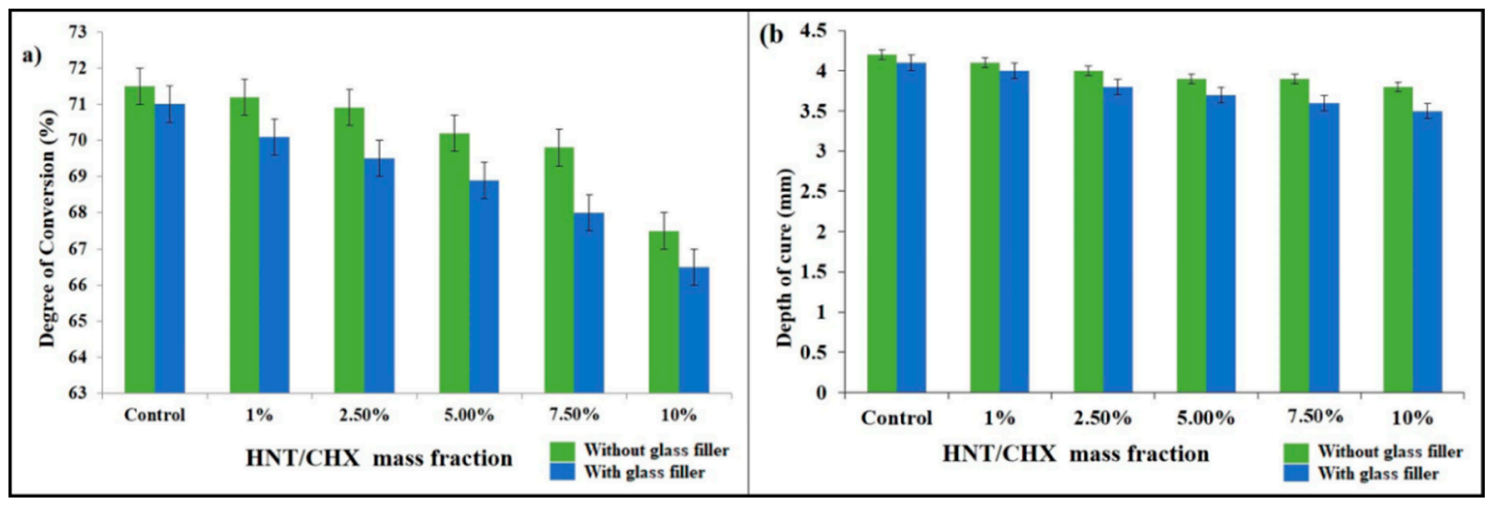

Figure 5. (a) Degree of conversion and (b) depth of cure of resin composites with varied amounts of HNT/CHX (1\%, 2.5\%, 5\%, 7.5\% and 10 wt. \%) $(p<0.05)$.

\subsubsection{Curing Depth}

The curing depth depends on the duration of and intensity of a curing unit. It also has a similar influence on the mechanical properties of a dental composite [37]. The results displayed that, as the amount of HNT/CHX filler increases, curing depth decreases. These results may be attributed to HNTs being opaque against the visible light and having a higher RF index (1.553-1.565), resulting in the lower monomer-to-polymer conversion and hence low curing depth of resultant dental composites (Figure 5) [38].

\subsubsection{Morphological Studies of Fractured Dental Resin Composites}

The SEM investigation of fracture surfaces of the control group (H1), 2.5\%, 5.0\% and $10 \mathrm{wt} . \%$ $\mathrm{HNT} / \mathrm{CHX}$ (H3, H4 and H5) and control group (G1), 2.5\%, 5.0\% and $10 \mathrm{wt} . \% \mathrm{HNT} / \mathrm{CHX}$ (G3, G4 and G5) were selected. After flexural tests, the fractured surfaces of dental composite were selected for further study. The control group displayed plane surface and fracture lines created from the tensile stress concentration point. In comparison, the fracture surface of the $2.5 \mathrm{wt}$ \% $\mathrm{HNT} / \mathrm{CHX}(\mathrm{H} 3)$ composite displayed a rough exterior, without illustrating any fracture lines. The ratio of filler in the composite matrix plays an important role in surface roughness; a higher filler ratio shows more surface coarseness.

The $5 \mathrm{wt} . \% \mathrm{HNT} / \mathrm{CHX}(\mathrm{H} 4)$ composite specimen showed very few clusters and no exposed nanotubes. The $10 \mathrm{wt} . \% \mathrm{HNT} / \mathrm{CHX}$ (H5) specimen demonstrated high surface roughness and heavy clusters of nanotubes (Figure 6). The clusters of nanotubes could create structural flaw and be the reason for the lower mechanical strength, which can lead to failure of the composite [33]. Moreover, the SEM results suggested that the incorporation of HNT/CHX in resin matrix resisted micro-cracks and efficiently sustained the applied mechanical force. Furthermore, at definite high force, the cracks created and formed a rough fracture surface that confirms the energy consumption during mechanical tests. Additionally, the fractured surface of the composite with glass fillers specimen showed similar results. Compared with $2.5 \mathrm{wt} . \% \mathrm{HNT} / \mathrm{CHX}$ (G3) and $5 \mathrm{wt.} \% \mathrm{HNT} / \mathrm{CHX}$ (G4), fractured surfaces of $10 \mathrm{wt} . \% \mathrm{HNT} / \mathrm{CHX}$ (G5) were inconsistently dispersed in the resin matrix with exposed nanotubes and glass fillers (Figure 7). 


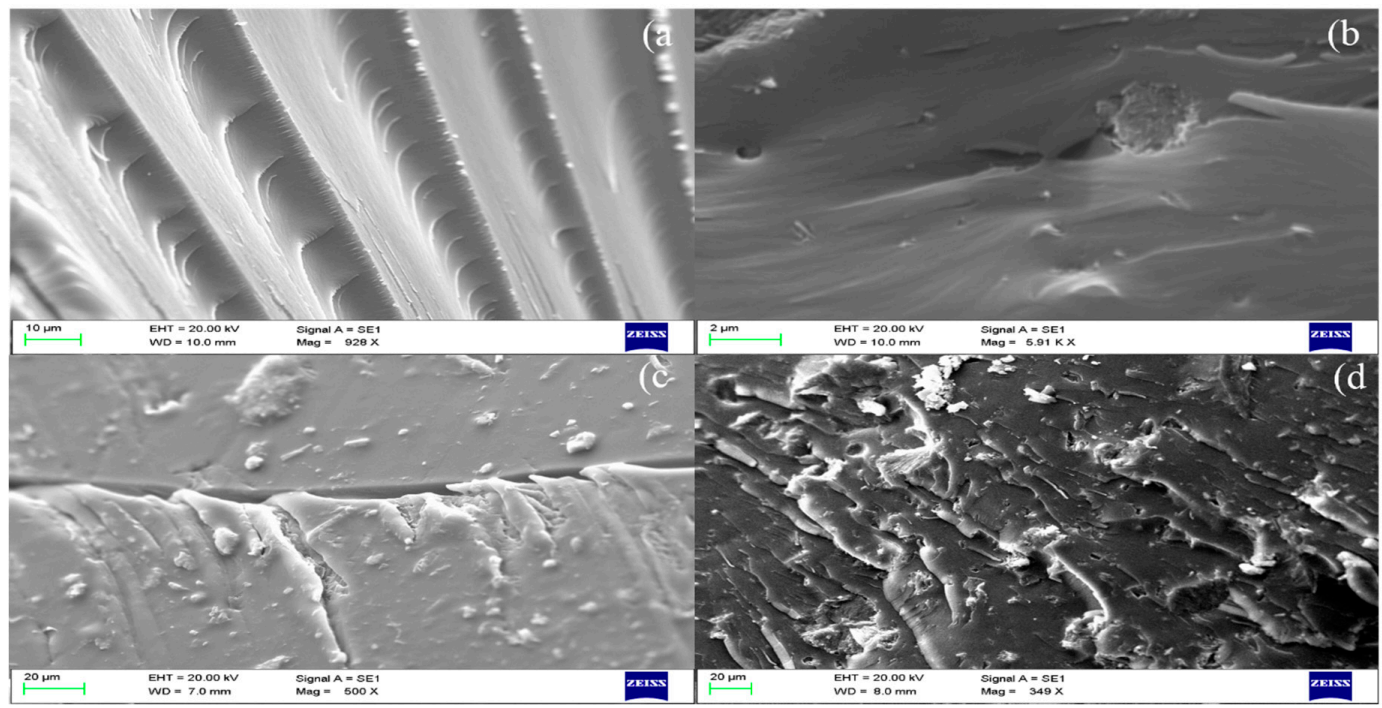

Figure 6. SEM images of the fractured surfaces of dental composite specimen without glass filler, at different magnifications: control group (a), composite with $2.5 \mathrm{wt}$.\% HNT/CHX (b), composite with $5 \mathrm{wt} . \% \mathrm{HNT} / \mathrm{CHX}$ (c) and composite with $10 \mathrm{wt}$.\% HNT/CHX focused on the Halloysite agglomerates (d).

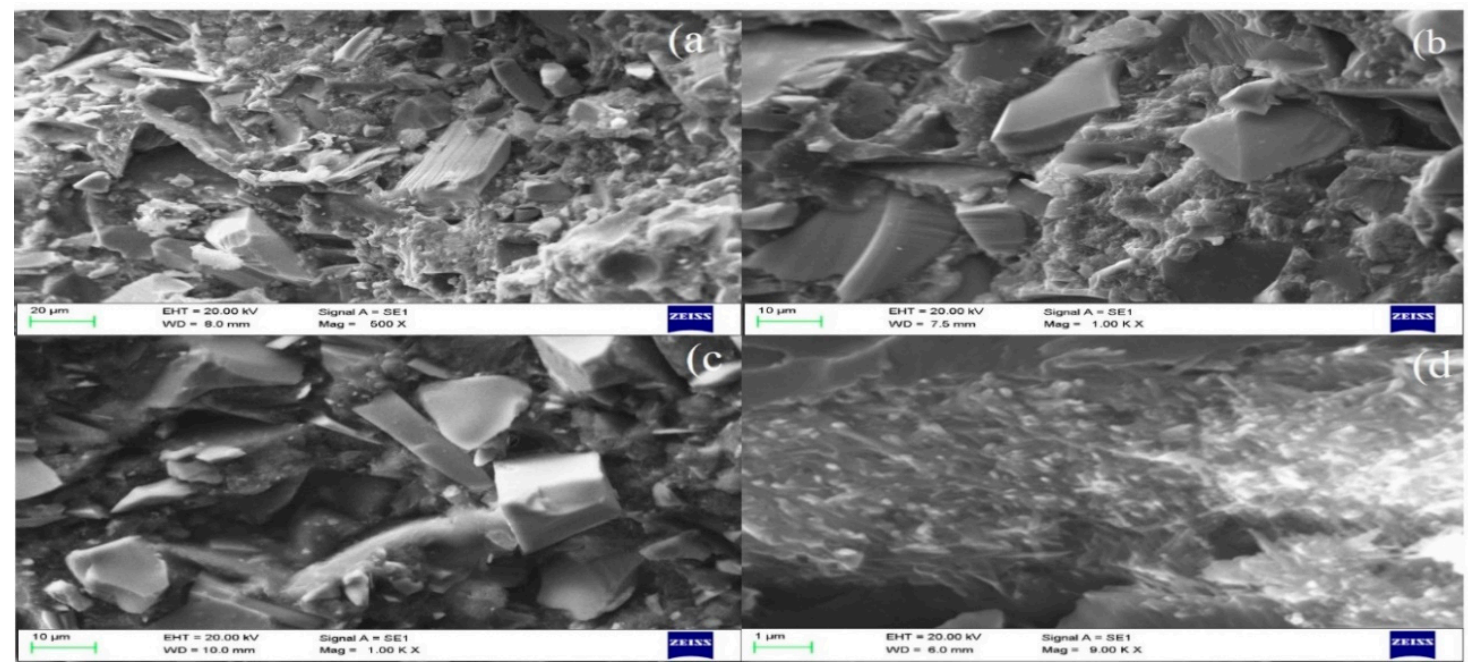

Figure 7. SEM images displaying the fractured surfaces of glass-filler-comprising composite specimen: control group (composite without HNT/CHX fillers) (a), composite with 2.5 wt.\% HNT/CHX (b), composite with $5 \mathrm{wt}$.\% HNT/CHX (c) and composite with $10 \mathrm{wt}$ \% HNT/CHX focused on the Halloysite agglomerates $(\mathbf{d})$.

\subsubsection{Antimicrobial Activity}

Staphylococcus mutans is the primary microorganism responsible for carious lesions and was used to assess the antibacterial activity of a resin composite incorporated with HNT/CHX fillers, by measuring the resultant inhibition zones. The antibacterial test of resin composite samples (without glass fillers) showed a diameter of inhibition zones as follows: control group H1 (0 mm), H2 (8 mm), $\mathrm{H} 3(8 \mathrm{~mm}), \mathrm{H} 4(8 \mathrm{~mm}), \mathrm{H} 5(9 \mathrm{~mm})$ and H6 $(10 \mathrm{~mm})$. Meanwhile, resin composite samples (with glass fillers and $\mathrm{HNT} / \mathrm{CHX})$ showed zone diameters as follows: control group G1 $(0 \mathrm{~mm}), \mathrm{G} 2(7 \mathrm{~mm})$, G3 $(7 \mathrm{~mm}), \mathrm{G} 4(8 \mathrm{~mm}), \mathrm{G} 5(8 \mathrm{~mm})$ and $\mathrm{G} 6(9 \mathrm{~mm})$.

These results showed that the composite samples with HNT/CHX are effective to prevent the growth of $S$. mutans. It was significantly visible by the larger diameter of bacterial inhibition zones which was corresponds to larger amounts of HNT/CHX in composites specimen. HNT did not 
show any zone of inhibition in the test, as it does not possess antibacterial properties naturally [39]. HNT did not show any bacterial activity, as it inherently lacks any antibacterial properties. Moreover, a significant difference was found in the inhibition efficiency between specimen groups with different amounts of filler concentration, suggesting that, as the filler proportion increases, the inhibition zone also increases [19,39] (Figure 4d).

\subsubsection{In Vitro Cytotoxicity Evaluation}

The cytotoxicity of the control and $5 \mathrm{wt}$ \% HNT/CHX specimen was assessed through MTT assay. NIH 3T3 fibroblast cells were used for the culture of extraction medium for 24, 48 and $72 \mathrm{~h}$. The results of cytotoxicity assay exhibited no significant difference between the control group and HNT/CHX specimen at all three time point. The NIH 3T3 fibroblast cells' viability for HNT/CHX resin composite at 24,48 and $72 \mathrm{~h}$ was $79 \%, 96 \%$ and $99 \%$, respectively, and the control group specimen showed $84.1 \%$, $99.9 \%$ and $100 \%$ cell viability. Moreover, cell viability over $70 \%$, which is considered safe, indicates low toxicity of a composite [40]. The results displayed lower cytotoxicity to NIH 3T3 fibroblast cells for an HNT/CHX composite specimen [40] (Figure 8).

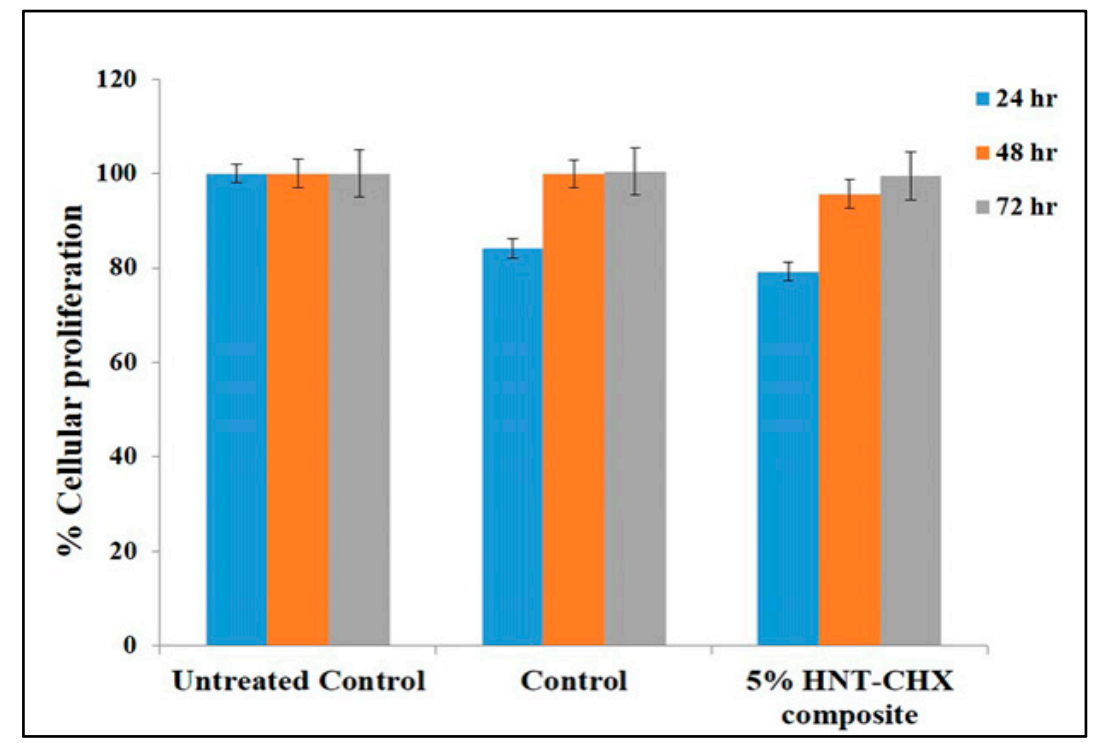

Figure 8. Cell proliferation assay. Composite samples were treated to NIH-3T3, and cytotoxicity was observed by using MTT assay. The $y$-axis represents percent proliferation, and the $x$-axis represents concentrations of compounds.

\section{Discussion}

Each and every material has its own strengths, as well as weaknesses, and is used for varying purposes. The incorporation of nanotechnology into materials science not only has potential to improve effectiveness in materials but also has a substantial impact on the development of new applications. Moreover, the introduction of nanotechnology in material fabrication enhanced properties of the final product substantially, specifically for the biomaterials [2-7]. The global demands for biomaterials with enhanced mechanical and biological properties have also increased substantially, particularly in dentistry. Different types of biomaterials, such as dental composites, are being used in the field of dentistry, for the benefit of the patients $[2,6]$. Sometimes, the factors such as poor oral health condition and marginal gaps existed due to polymerizing shrinkage, causing secondary caries and hence failure of the dental restoration $[19,21,39]$. The incorporation of nanotechnology-based dental-restorative materials with antibacterial-agent-loaded nano-filler can decrease the polymerization shrinkage and directly prevent biofilm formation on tooth surface [41]. Thus, reducing the formation of bacterial biofilm on the tooth surface ultimately results in improved dental hygiene, and the prevention of 
secondary caries is an important means for the lifespan of the composite restoration. Our earlier studies have also displayed that dental composites comprising such nano-fillers can deliver superior mechanical strength and antibacterial properties simultaneously $[19,39]$.

Our study not only shows the possibility to use HNT/CHX as a promising filler for the fabrication of dental composites but also confirm its favorable effects on mechanical and biological properties.

HNTs have been used as a nanocarrier system for drug delivery and also act as filler in the development of novel dental composites [15,18,19,39]. Different studies pertaining to CHX as an antibacterial agent for the fabrication of dental composites have been reported $[5,21]$. In this current study, HNTs were used to entrap CHX. This resultant CHX loaded HNTs were not only used for antibacterial activity but also as an alternative filler for dental-composite fabrication with amicable biocompatibility. Moreover, the results of our study are in good agreement with the earlier findings [19,39,42-44].

The TEM analysis (Figure 1) reveals an increase in the internal diameter of HNT lumen and dark spots at the surface of HNT, confirming the loading of CHX in HNT [18,19]. The XRD pattern (Figure 2) also showed the characteristic peaks of HNT/CHX at $2 \theta$ were consistent with the standard HNT peaks, indicating that the CHX loading did not change the crystalline structure of HNTs [18,19].

Figure 4 shows the results of the mechanical properties of all composite groups tested by UTM. The comparison between the composite comprising mass faction of HNT/CHX without glass fillers and the resin composite with glass filler was shown. The resin composite samples devoid of glass fillers showed that, among all the specimen groups, the $5 \mathrm{wt} . \% \mathrm{HNT} / \mathrm{CHX}$ (H4) composite group exhibited significantly high Compressive Strength (CS), Flexural Modulus (FM) and Flexural Strength (FS), as compared to the control group. Moreover, the resin composite group with glass fillers, $5 \mathrm{wt} . \%$ HNT/CHX (G4) composite specimen, showed much higher mechanical strengths than other groups. The uniform distribution of the Halloysite nanotubes in the resin matrix and high conversion of double bonds of monomer to polymer may be responsible for its higher mechanical properties [45]. Moreover, DC results of composites groups showed a non-significant difference $(p<0.05)$, indicating that different amounts of HNT/CHX in composites have negligible effects on their conversion [35,36]. Furthermore, both composite groups, with and without glass fillers, showed a negligible decrease in curing depth.

Cadenaro et al. reported that high concentrations ( $>5 \%)$ of $\mathrm{CHX}$ in resin have adverse effect on DC and decrease the elastic modulus compared to the controls [5]. Meanwhile, in the current study, CHX was entrapped inside the nanotubular-shaped HNTs at a much lower concentration $(5 \mathrm{wt} . \%$ HNT/CHX), which further prevents its adverse effect on the DC of the dental composite. Moreover, by using the nanostructured Halloysite nanotubes, mechanical properties of dental composite do not get compromised however it enhanced significantly compare to control group.

A study pertaining to doxycycline-loaded HNTs (DOX HNTs) as an antibacterial filler for matrix metalloproteinase (MMP) inhibition to preserve resin/dentin bond stability has been reported [4]. Doxycycline-loaded HNTs (at $10 \mathrm{wt} . \%$ ) exhibits antibacterial activity against $S$. mutans with $2.3 \mathrm{~mm}$ as zone of inhibition, while our study reported an $8 \mathrm{~mm}$ zone of inhibition, at (5 wt.\%), which shows better antibacterial activity ( $>3$ times) of the dental composite. In one of our recent published studies, we used Farnesol-loaded HNTs as a filler for the fabrication of a dental composite [19], in which 7-13 wt.\% of Farnesol-loaded HNTs in composite samples gave the high mechanical strength and while DC values decreases considerably at high concentration. While in current study, significant mechanical strength was found at $5 \mathrm{wt} . \% \mathrm{HNT} / \mathrm{CHX}$ and decrease in DC values was negligible.

The SEM images of fractured surfaces of composite samples in Figures 6 and 7 showed that the $\mathrm{HNT} / \mathrm{CHX}$ was homogeneously distributed in the resin matrix at a low mass fraction of HNT/CHX (2.5 and $5 \mathrm{wt} . \%)$. However, a higher mass fraction of HNT/CHX (10 wt.\%) showed several clusters of agglomerates and hence lower strength for the composite. These agglomerates could be loosely distributed in the resin matrix and act as structural defects, which could greatly reduce the mechanical strength of the dental resin composites. 
The results also exhibit potent antibacterial activity against $S$. mutans by the HNT/CHX dental composite specimen. The maximum zone of inhibition in the antibacterial test was achieved with the composite specimen containing high mass fraction of HNT/CHX. This antibacterial study indicated that the higher the mass fraction of HNT/CHX in resin matrix, the better the antibacterial effect against S. mutans. In this study, the cytotoxicity of HNT/CHX dental composite specimens was evaluated by MTT Tetrazolium test method to NIH 3T3 cell lines (mouse embryonic fibroblast). Moreover, negligible cytotoxicity was found on NIH 3T3 cell lines between the tested groups and according to ISO 10993-5 guidelines; cell viability values above $70 \%$ have no relevant cytotoxicity for dental composites $[40,45,46]$. Hence, $\mathrm{HNT} / \mathrm{CHX}$ can be highly considered as a promising filler for dental composites.

\section{Conclusions}

In this study, an HNT/CHX-comprising experimental dental resin composite was successfully prepared. The results displayed enhanced mechanical and biological properties of dental resin composite by reinforcement with HNT/CHX fillers. Moreover, this study also showcases a good utilization of HNT/CHX as filler for experimental dental resin composites with dual essential properties. All the groups presented enhanced properties, and among them, $5 \mathrm{wt} . \% \mathrm{HNT} / \mathrm{CHX}$ (H4) and $5 \mathrm{wt} . \%$ HNT/CHX (G4) displayed the best results, with high mechanical strength and exceptional antimicrobial activity. Moreover, they also displayed a satisfactory degree of conversion and curing-depth values. Additionally, the HNT/CHX resin composite was found to be nontoxic on NIH3T3 cells in MTT assay. The results of our study displayed that the HNT/CHX resin composite delivers extra mechanical, as well as antimicrobial, properties, and it can be used as a potential dental filler for clinical dental applications.

Author Contributions: Conceptualization, T.B. and D.R.; data curation, T.B.; formal analysis, P.K.; investigation, T.B.; methodology, T.B. and D.R.; project administration, D.R.; resources, T.B. and D.R.; software, T.B. and P.K.; supervision, D.R.; validation, T.B. and P.K.; visualization, T.B.; writing-original draft, T.B. and D.R.; writing-review and editing, D.R. All authors have read and agreed to the published version of the manuscript.

Funding: This research received no external funding.

Conflicts of Interest: The authors declare no conflict of interest.

\section{References}

1. Bourgeois, D.; Inquimbert, C.; Ottolenghi, L.; Carrouel, F. Periodontal pathogens as risk factors of cardiovascular diseases, diabetes, rheumatoid arthritis, cancer, and chronic obstructive pulmonary disease is there cause for consideration. Microorganisms 2019, 10, 424. [CrossRef]

2. Frankenberger, R.; Pashley, D.H.; Reich, S.M.; Lohbauer, U.; Petschelt, A.; Tay, F.R. Characterisation of resin-dentine interfaces by compressive cyclic loading. Biomaterials 2005, 26, 2043-2052. [CrossRef] [PubMed]

3. Liu, Y.; Tjäderhane, L.; Breschi, L.; Mazzoni, A.; Li, N.; Mao, J.; Pashley, D.H.; Tay, F.R. Limitations in bonding to dentin and experimental strategies to prevent bond degradation. J. Dent. Res. 2011, 90, 953-968. [CrossRef] [PubMed]

4. Palasuk, J.; Windsor, L.J.; Platt, J.A.; Lvov, Y.; Geraldeli, S.; Bottino, M.C. Doxycycline-loaded nanotube-modified adhesives inhibit MMP in a dose-dependent fashion. Clin. Oral Investig. 2018, 22, 1243-1252. [CrossRef] [PubMed]

5. Cadenaro, M.; Pashley, D.H.; Marchesi, G.; Carrilho, M.; Antoniolli, F.; Mazzoni, A.; Tay, F.R.; Di Lenarda, R.; Breschi, L. Influence of chlorhexidine on the degree of conversion and E-modulus of experimental adhesive blends. Dent. Mater. 2009, 25, 1269-1274. [CrossRef] [PubMed]

6. Frassetto, A.; Breschi, L.; Turco, G.; Marchesi, G.; Di Lenarda, R.; Tay, F.R.; Pashley, D.H.; Cadenaro, M. Mechanisms of degradation of the hybrid layer in adhesive dentistry and therapeutic agents to improve bond durability-A literature review. Dent. Mater. 2016, 32, 41-53. [CrossRef]

7. Pashley, D.H.; Tay, F.R.; Breschi, L.; Tjäderhane, L.; Carvalho, R.M.; Carrilho, M.; Tezvergil-Mutluay, A. State of the art etch-and-rinse adhesives. Dent. Mater. 2011, 27, 1-6. [CrossRef]

8. Mjör, I.A. The reasons for replacement and the age of failed restorations in general dental practice. Acta Odontol. Scand. 1997, 55, 58-63. [CrossRef] 
9. Khvostenko, D.; Salehi, S.; Naleway, S.E.; Hilton, T.J.; Ferracane, J.L.; Mitchell, J.C.; Kruzic, J.J. Cyclic mechanical loading promotes bacterial penetration along composite restoration marginal gaps. Dent. Mater. 2015, 31, 702-710. [CrossRef]

10. Rawtani, D.; Agrawal, Y.K. Multifarious applications of halloysite nanotubes: A review. Rev. Adv. Mater. Sci. 2012, 30, 282-295.

11. Magrez, A.; Kasas, S.; Salicio, V.; Pasquier, N.; Seo, J.W.; Celio, M.; Catsicas, S.; Schwaller, B.; Forró, L. Cellular toxicity of carbon-based nanomaterials. Nano Lett. 2006, 14, 1121-1125. [CrossRef] [PubMed]

12. Fakhrullina, G.I.; Akhatova, F.S.; Lvov, Y.M.; Fakhrullin, R.F. Toxicity of halloysite clay nanotubes in vivo: A Caenorhabditiselegans study. Environ. Sci. 2015, 2, 54-59. [CrossRef]

13. Salim, N.; Moore, C.; Silikas, N.; Satterthwaite, J.; Rautemaa, R. Chlorhexidine is a highly effective topical broad-spectrum agent against Candida spp. Int. J. Antimicrob. Agents 2013, 41, 65-69. [CrossRef] [PubMed]

14. Basrani, B. Chlorhexidinegluconate. Aust. Endod. J. 2005, 31, 48-52. [CrossRef]

15. Qi, R.; Guo, R.; Zheng, F.; Liu, H.; Yu, J.; Shi, X. Controlled release and antibacterial activity of antibiotic-loaded electrospun halloysite/poly (lactic-co-glycolic acid) composite nanofibers. Colloids Surf. B Biointerfaces 2013, 110, 148-155. [CrossRef]

16. Zandinejad, A.A.; Atai, M.; Pahlevan, A. The effect of ceramic and porous fillers on the mechanical properties of experimental dental composites. Dent. Mater. 2006, 22, 382-387. [CrossRef]

17. Wegehaupt, F.J.; Lunghi, N.; Belibasakis, G.N.; Attin, T. Influence of light-curing distance on degree of conversion and cytotoxicity of etch-and-rinse and self-etch adhesives. BMC Oral Health 2017, 17, 12. [CrossRef]

18. Rawtani, D.; Pandey, G.; Tharmavaram, M.; Pathak, P.; Akkireddy, S.; Agrawal, Y.K. Development of a novel 'nanocarrier'system based on Halloysite Nanotubes to overcome the complexation of ciprofloxacin with iron: An in vitro approach. Appl. Clay Sci. 2017, 150, 293-302. [CrossRef]

19. Barot, T.; Rawtani, D.; Kulkarni, P.; Hussain, C.M.; Akkireddy, S. Physicochemical and biological assessment of flowable resin composites incorporated with farnesol loaded halloysite nanotubes for dental applications. J. Mech. Behav. Biomed. Mater. 2020, 7, 103675. [CrossRef]

20. Chen, H.; Wang, R.; Zhang, J.; Hua, H.; Zhu, M. Synthesis of core-shell structured ZnO@ m-SiO 2 with excellent reinforcing effect and antimicrobial activity for dental resin composites. Dent. Mater. 2018, 34, 1846-1855. [CrossRef]

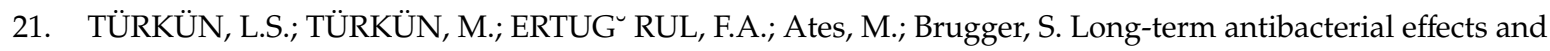
physical properties of a chlorhexidine-containing glass ionomer cement. J. Esthet. Restor. Dent. 2008, 20, 29-44. [CrossRef]

22. Imazato, S.; Imai, T.; Russell, R.R.; Torii, M.; Ebisu, S. Antibacterial activity of cured dental resin incorporating the antibacterial monomer MDPB and an adhesion-promoting monomer. J. Biomed. Mater. Res. Off. J. Soc. Biomater. Jpn. Soc. Biomater. Aust. Soc. Biomater. 1998, 39, 511-515. [CrossRef]

23. Hotwani, K.; Thosar, N.; Baliga, S.; Bundale, S.; Sharma, K. Antibacterial effects of hybrid tooth colored restorative materials against Streptococcus mutans: An in vitro analysis. J. Conserv. Dent. 2013, 16, 319. [CrossRef] [PubMed]

24. Tumscitz, D.B.; Laxe, L.A.; Pascoal, A.C.; HIRATA JUNIOR, R.; Lins, R.X. Cytotoxicity of three light-cured resin cements on 3 T3 fibroblasts. Rev Fac Odontol Pernambuco. 2017, 46, 203-207. [CrossRef]

25. Kulkarni, P.; Rawtani, D.; Barot, T. Formulation and optimization of long acting dual niosomes using Box-Behnken experimental design method for combinative delivery of Ethionamide and D-cycloserine in Tuberculosis treatment. Colloids Surf. Physicochem. Eng. Asp. A 2019, 565, 131-142. [CrossRef]

26. De Silva, R.T.; Dissanayake, R.K.; Mantilaka, M.P.; Wijesinghe, W.S.; Kaleel, S.S.; Premachandra, T.N.; Weerasinghe, L.; Amaratunga, G.A.; De Silva, K.N. Drug-Loaded Halloysite Nanotube-Reinforced Electrospun Alginate-Based Nanofibrous Scaffolds with Sustained Antimicrobial Protection. ACS Appl. Mater. Interfaces 2018, 10, 33913-33922. [CrossRef] [PubMed]

27. Lvov, Y.M.; Shchukin, D.G.; Mohwald, H.; Price, R.R. Halloysite clay nanotubes for controlled release of protective agents. ACS Nano 2008, 2, 814-820. [CrossRef] [PubMed]

28. Lvov, Y.M.; DeVilliers, M.M.; Fakhrullin, R.F. The application of halloysite tubule nanoclay in drug delivery. Expert Opin. Drug Deliv. 2016, 13, 977-986. [CrossRef] [PubMed]

29. Du, M.; Guo, B.; Jia, D. Thermal stability and flame retardant effects of halloysite nanotubes on poly (propylene). Eur. Polym. J. 2006, 42, 1362-1369. [CrossRef] 
30. Wu, Y.; Yang, Y.; Liu, H.; Yao, X.; Leng, F.; Chen, Y.; Tian, W. Long-term antibacterial protected cotton fabric coating by controlled release of chlorhexidine gluconate from halloysite nanotubes. Rsc Adv. 2017, 7, 18917-18925. [CrossRef]

31. Levis, S.R.; Deasy, P.B. Characterisation of halloysite for use as a microtubular drug delivery system. Int. J. Pharm. 2002, 243, 125-134. [CrossRef]

32. Yang, J.H.; Lee, J.H.; Ryu, H.J.; Elzatahry, A.A.; Alothman, Z.A.; Choy, J.H. Drug-clay nanohybrids as sustained delivery systems. Appl. Clay Sci. 2016, 130, 20-32. [CrossRef]

33. Chen, Q.; Zhao, Y.; Wu, W.; Xu, T.; Fong, H. Fabrication and evaluation of Bis-GMA/TEGDMA dental resins/composites containing halloysite nanotubes. Dent. Mater. 2012, 28, 1071-1079. [CrossRef] [PubMed]

34. Bottino, M.C.; Batarseh, G.; Palasuk, J.; Alkatheeri, M.S.; Windsor, L.J.; Platt, J.A. Nanotube-modified dentin adhesive-Physicochemical and dentin bonding characterizations. Dent. Mater. 2013, 29, 1158-1165. [CrossRef]

35. CHUNG, K.H.; Greener, E.H. Correlation between degree of conversion, filler concentration and mechanical properties of posterior composite resins. J. Oral Rehabil. 1990, 17, 487-494. [CrossRef]

36. Eldiwany, M.; Powers, J.M.; George, L.A. Mechanical properties of direct and post-cured composites. Am. J. Dent. 1993, 6, 222-224.

37. Lovell, L.G.; Lu, H.; Elliott, J.E.; Stansbury, J.W.; Bowman, C.N. The effect of cure rate on the mechanical properties of dental resins. Dent. Mater. 2001, 17, 504-511. [CrossRef]

38. Rooj, S.; Das, A.; Thakur, V.; Mahaling, R.N.; Bhowmick, A.K.; Heinrich, G. Preparation and properties of natural nanocomposites based on natural rubber and naturally occurring halloysite nanotubes. Mater. Des. 2010, 31, 2151-2156. [CrossRef]

39. Barot, T.; Rawtani, D.; Kulkarni, P. Physicochemical and biological assessment of silver nanoparticles immobilized Halloysite nanotubes-based resin composite for dental applications. Heliyon 2020, 6, e03601. [CrossRef]

40. Kangwansupamonkon, W.; Lauruengtana, V.; Surassmo, S.; Ruktanonchai, U. Antibacterial effect of apatite-coated titanium dioxide for textiles applications. Nanomed. Nanotechnol. Biol. Med. 2009, 5, $240-249$. [CrossRef]

41. Imazato, S. Bio-active restorative materials with antibacterial effects: New dimension of innovation in restorative dentistry. Dent. Mater. J. 2009, 28, 11-19. [CrossRef] [PubMed]

42. Ariga, K.; Lvov, Y.M.; Kawakami, K.; Ji, Q.; Hill, J.P. Layer-by-layer self-assembled shells for drug delivery. Adv. Drug Deliv. Rev. 2011, 63, 762-771. [CrossRef] [PubMed]

43. Lvov, Y.; Aerov, A.; Fakhrullin, R. Clay nanotube encapsulation for functional biocomposites. Adv. Colloid Interface Sci. 2014, 207, 189-198. [CrossRef] [PubMed]

44. Pereira-Cenci, T.; Cenci, M.S.; Fedorowicz, Z.; Azevedo, M. Antibacterial agents in composite restorations for the prevention of dental caries. Cochrane Database Syst. Rev. 2013, 12. [CrossRef]

45. Abdullayev, E.; Lvov, Y. Halloysite clay nanotubes as a ceramic "skeleton" for functional biopolymer composites with sustained drug release. J. Mater. Chem. B 2013, 1, 2894-2903. [CrossRef]

46. Miao, X.; Li, Y.; Zhang, Q.; Zhu, M.; Wang, H. Low shrinkage light curable dental nanocomposites using $\mathrm{SiO}_{2}$ microspheres as fillers. Mater. Sci. Eng. C 2012, 32, 2115-2121. [CrossRef]

(C) 2020 by the authors. Licensee MDPI, Basel, Switzerland. This article is an open access article distributed under the terms and conditions of the Creative Commons Attribution (CC BY) license (http://creativecommons.org/licenses/by/4.0/). 